\title{
Behavioral Responses of Daphnia Magna to Stresses of Chemicals with Different Toxic Characteristics
}

\author{
Zongming Ren $\cdot$ Zhiliang Li $\cdot$ Mei Ma \\ Zijian Wang $\cdot$ Rongshu Fu
}

Received: 20 February 2008/Accepted: 9 October 2008/Published online: 31 October 2008

(C) Springer Science+Business Media, LLC 2008

\begin{abstract}
Behavior of an organism is affected by exposure to toxic chemicals. However, less has been known about behavioral responses of an organism to stresses of toxic chemicals with different toxic characteristics. In present work, Daphnia magna Straus was exposed to gradient concentrations of deltamethrin, chlorothalonil and nitrofen and the behavioral changes of Daphnia magna under different stress were examined. The results showed that the behavioral responses of Daphnia magna to the tested chemicals were affected in general by exposure concentration, rather than toxic characteristics of the chemicals. The duration of avoidance response (DAR) was in a power regression relationship with the toxic unit (TU), defined as the ratio of exposure concentration of the tested chemical to its $\mathrm{LC}_{50-48}$. DAR was independent of the toxic characteristics of chemicals. However, significant behavior adjustment could be observed after exposure to deltamethrin while only step-by-step decrease in behavior strength could be observed when exposed to chlorothalonil and nitrofen. It was suggested from the observation that
\end{abstract}

Z. Ren $\cdot$ Z. Li $\cdot$ M. Ma $\cdot$ Z. Wang $(\bowtie)$

State Key Laboratory of Environmental Aquatic Chemistry, Research Center for Eco-Environmental Science, Chinese Academy of Science, Shuangqing Rd 18, Haidian District, P.O. Box 2871, Beijing 100085, China

e-mail: wangzj@rcees.ac.cn

Z. Ren

Yantai Institute of Coastal Zone Research for Sustainable Development, Chinese Academy of Sciences, Yantai 264000, China

Z. Ren $\cdot$ Z. Li $\cdot$ R. Fu

College of Life Science, Shandong Normal University,

Jinan 250014, China avoidance behaviors of Daphnia magna to exposures of chemicals with different toxic characteristics could be similar, while their specific response could be different.

Keywords Behavioral responses - Daphnia magna . Toxic characteristics

Deltamethrin, chlorothalonil and nitrofen are extensively used in agriculture, silviculture, and urban settings and can enter surface waters through rainfall runoff, spray drift, or atmospheric deposition subsequently impacting aquatic biota. The ways that they exert their toxicity are different, though they all cause toxic effects on aquatic organisms. Deltamethrin is a type II pyrethroid (Soderlund and Bloomquist 1989) which has been encouraged to use in intensive agriculture as replacement for more toxic insecticides such as organophosphates that exert their toxicity by inhibiting acetyl cholinesterase (AChE) of organisms (Moore and Waring 2001; Duquesne 2006). Its principal molecular mode of action is the modification of the sodium channel kinetics leading to hyperexcitation of the nervous system (Narahashi et al. 1992). It induces neurotoxicity and the effects of deltamethrin on nervous, respiratory, and hematological systems in organisms are reported (Wiles and Jepson 1994; Şener Ural and Sağlam 2005; Pimpão et al. 2007). Chlorothalonil is a widely applied organochlorine nonsystemic fungicide in rural and urban environments. It inhibits important cellular enzymes (i.e., NADPH oxidase) by binding to the sulphydryl groups altering metabolic functions in cellular respiration (Caux et al. 1996). It also depletes glutathione (GSH), a non-enzymatic reducing agent involved in cell detoxification (Tillman et al. 1973). The effects of chlorothalonil on the survival of Daphnia magna (Ernst et al. 1991; Fernández-Alba et al. 
2002) and the reproduction of the meiobenthic estuarine copepod Amphiascus tenuiremis (Bejarano et al. 2005) are reported. Nitrofen, which is a diphenyl ether herbicide, interferes with thyroid hormone and/or retinoic acid signaling and induces organ damage (Manson 1986; Brandsma et al. 1994; Mascrez et al. 1998; Greer et al. 2003) and it produces a spectrum of fetal abnormalities in rodents (Kling et al. 2005).

The freshwater cladoceran Daphnia magna Straus are normally considered as sensitive to contaminants (Sturm and Hansen 1999; Rosa et al. 2006). The species have often been used in bioassays and environmental monitoring of aquatic systems due to the ease and economy of maintaining cultures (Tomasik and Warren 1996; MartínezJerónimo et al. 2005; Heckmann et al. 2007). The initial response of an individual to contaminant exposure is a possible change in its behavior, due to visual or chemoreception (olfaction, taste) damage (Scarfe et al. 1983; Riddell et al. 2005; Mandrillon and Saglio 2007). Changes in the movement behavior of organisms can therefore be used as a suitable indicator in ecotoxicological risk assessment. According to previous research (Steele et al. 1989; Saglio and Trijasse 1996; Eriksson Wiklund et al. 2006), avoidance of the organism to contaminants is an adaptive behavior that may reduce exposure to harmful conditions and failure to avoid exposure may result in reduced fitness and survival, eventually leading to detrimental effects. The movement patterns of Daphnia magna have many different components and the behavioral responses of Daphnia magna to different contaminants are reported (Untersteiner et al. 2003; Reynaldi et al. 2006).

The current study was undertaken to assess whether different contaminants (Deltamethrin, Chlorothalonil and Nitrofen) with different toxic characteristics would induce different effects on the behavioral responses of Daphnia magna or not. Meanwhile, avoidance responses as the first behavior modulation of Daphnia magna to try to escape from the polluted environment were investigated to discuss the relationship between the duration of avoidance response (DAR) and their $\mathrm{LC}_{50-48}$ based toxic unit (TU).

\section{Materials and Methods}

The experimental Daphnia magna (24-h young) were obtained from the Chinese Environmental Science Academy and cultured in our laboratory for more than 3 generations. The general culture of Daphnia magna was maintained in the Standard Reference Water (SRW) (ISO 1996a), at $20 \pm 2^{\circ} \mathrm{C}$ with 16L: 8D photoperiod. Daphnia magna were fed with a suspension of batch-cultured green algae (Scenedesmus obliquus). Before the exposure experiments, the gravid female Daphnia magna were taken out and cultured individually in 50-mL glass beakers of SRW until they oviposited.

Healthy neonates (about $24 \mathrm{~h}$ ) from the second and following clutches were applied in the study. During the individual culture of female Daphnia magna with eggs, the growth medium was renewed regularly and Daphnia magna were fed with Scenedesmus obliquus algae three times a week. Before feeding Daphnia magna, the culture medium of Scenedesmus obliquus was filtered and then diluted by SRW until the concentration reached $1 \times 10^{5}$ cells $/ \mathrm{mL}$. The quantity of the algae was about $1 \%$ beaker volume.

Deltamethrin, chlorothalonil and nitrofen were purchased from J\&K Chemical Ltd (Beijing). All compounds were technical grade ( $>95 \%$ purity). Stock solutions (stored at $4{ }^{\circ} \mathrm{C}$ until use) with proper concentration of each chemical were prepared in dimethyl sulfoxide (DMSO, analytical pure) with appropriate aliquots used to make each test solution of a specific concentration. The concentration of DMSO in water was less than $0.5 \%$. A study has shown that DMSO of such concentration would neither lead to acute toxicity to Daphnia magna nor affect the mobility of Daphnia magna (Sandbacka et al. 2000).

Preliminary acute toxicity test was conducted in order to obtain the 48-h median lethal concentrations $\left(\mathrm{LC}_{50-48}\right)$ to Daphnia magna for the three contaminants, following the standard protocol for Daphnia magna acute test (ISO 1996b). Death of Daphnia magna was defined as the inability to swim for more than a few strokes within $15 \mathrm{~s}$ after gentle agitation of the test vessel (Villegas-Navarro et al. 1999).

In this study, $\mathrm{LC}_{50-48}$ was taken as one toxic unit (1 TU) and the behavioral responses of Daphnia magna to five concentration gradients, i.e., $0.1 \mathrm{TU}, 1 \mathrm{TU}, 2 \mathrm{TU}$, $5 \mathrm{TU}$, and $10 \mathrm{TU}$, were evaluated using a biomonitoring device (Gerhardt et al. 2002). The device was made up of eight test chambers ( $2 \mathrm{~cm}$ long, $1.5 \mathrm{~cm}$ in diameter), which were closed off on both sides with nylon nets $(250 \mu \mathrm{m})$ and matched with the size of the tested organisms. Five healthy neonates about $24 \mathrm{~h}$ of Daphnia magna were selected at random and placed in each test chamber. In the device, a pair of electrodes at the walls of the test chambers emits a high frequency signal of altering current, which was received by a second pair of non current-carrying electrodes. The movement of test organism will cause signal alternation, which was transformed by the A/D transformer and the signal changes were analyzed automatically. Behavior strength, which was defined as the intensity of behavior parameters representing motility, was detected directly by the system, and full behavior strength of tested organisms was regarded as 1 unit. The monitoring data are analyzed 
using functions of "alarm generation", which is based on the alarm algorithm in an ARIMA-model. The data were sampled automatically every $10 \mathrm{~min}$ and 6 data records in $1 \mathrm{~h}$ were used to calculate the average. The averages within 48-h exposure were used to assess the behavioral responses. Controlled the flow rate of each test chamber about $2 \mathrm{~L}$ per hour, and it was proved to have no effect on the motility of Daphnia magna (Ren et al. 2006).

During the studies, laboratory conditions were kept the same as in the culturing room. All determinations were repeated three times. Control groups were tested in a solvent solution (SRW 99.5\% + 0.5\% DMSO). No food was added during the experiments.

The $\mathrm{LC}_{50-48}$ values were calculated with linear interpolation using SPSS 10.0. One-way analysis of variance (ANOVA) of SPSS 10.0 was performed to compare the differences of behavioral responses of Daphnia magna exposed to different contaminants with the control with a
$95 \%$ confidence limit. Data were presented by mean of the three repetitions and curve fitting was performed with Origin 7.0.

\section{Results and Discussion}

The $\mathrm{LC}_{50-48}$ for Daphnia magna was $0.45 \mu \mathrm{g} / \mathrm{L}$ for deltamethrin, $75 \mu \mathrm{g} / \mathrm{L}$ for chlorothalonil, and $70 \mu \mathrm{g} / \mathrm{L}$ for nitrofen, respectively (Table 1). Though these results were close to previous research, pollutant levels of these chemicals to Daphnia magna were not measured here. Therefore, the exposure doses were relative.

Figures 1, 2, 3 showed the effects of deltamethrin, chlorothalonil and nitrofen on the behavioral responses of Daphnia magna in 48-h exposure. Within the control group, no significant changes in behavioral responses were detected. In the case of deltamethrin exposure, behavior

Table 1 The acute toxic effects of deltamethrin, chlorothalonil and nitrofen on different organisms

\begin{tabular}{|c|c|c|c|c|c|}
\hline \multirow[t]{2}{*}{ Chemicals } & \multirow[t]{2}{*}{ Test organisms } & \multicolumn{3}{|c|}{$\mathrm{LC}_{50}$ values $(\mu \mathrm{g} / \mathrm{L})$} & \multirow[t]{2}{*}{ References } \\
\hline & & $\mathrm{LC}_{50-24}$ & $\mathrm{LC}_{50-48}$ & $\mathrm{LC}_{50-96}$ & \\
\hline \multirow[t]{3}{*}{ Deltamethrin } & Fish & & & $0.4-2.0$ & WHO (World Health Organization) (1990) \\
\hline & Oncorhynchus & 3.19 & 1.66 & 0.70 & Şener Ural and Sağlam (2005) \\
\hline & Daphnia magna & & 0.45 & & Author \\
\hline \multirow[t]{5}{*}{ Chlorothalonil } & Daphnia magna & & 28 & & Fernández-Alba et al. (2002) \\
\hline & & & $81-113$ & & Ernst et al. (1991) \\
\hline & & & 75 & & Author \\
\hline & Oysters & 108.5 & & & Baier-Anderson and Anderson (2000) \\
\hline & Amphiascus tenuiremis & & & 59.4 & Bejarano et al. (2005) \\
\hline Nitrofen & Daphnia magna & & 70 & & Author \\
\hline
\end{tabular}

Fig. 1 The effects of deltamethrin on the behavioral responses of Daphnia magna in 48-h exposure $(* p \leq 0.05)$

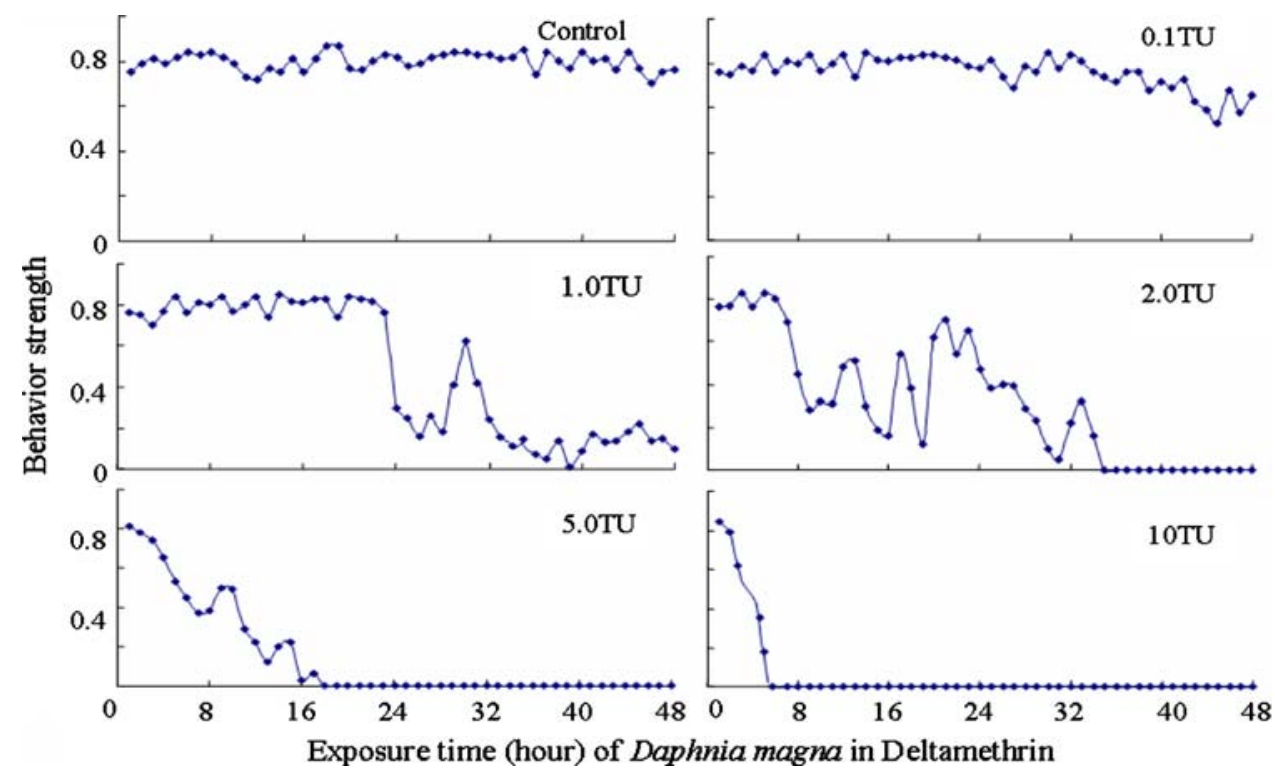


Fig. 2 The effects of responses of Daphnia magna in 48-h exposure $(* p \leq 0.05)$ chlorothalonil on the behavioral

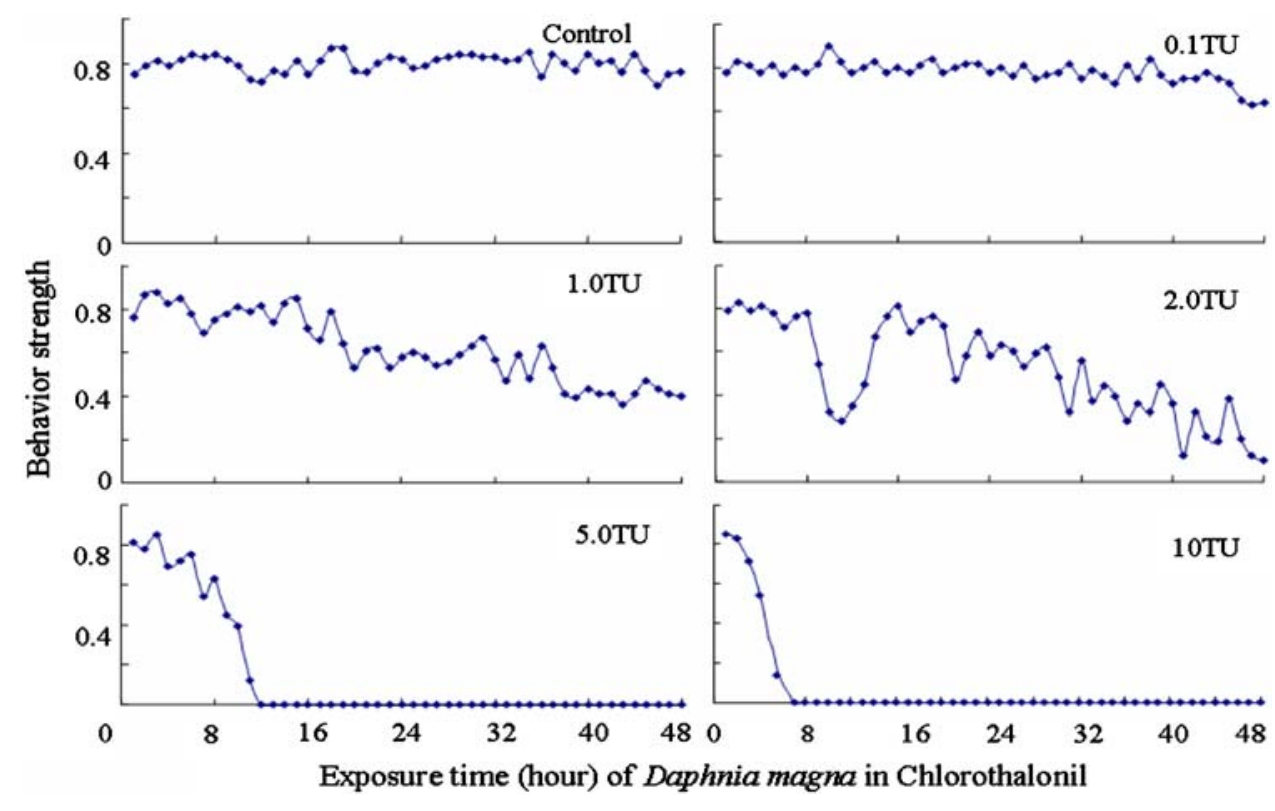

Fig. 3 The effects of nitrofen on the behavioral responses of Daphnia magna in 48-h exposure $\left({ }^{*} p \leq 0.05\right)$

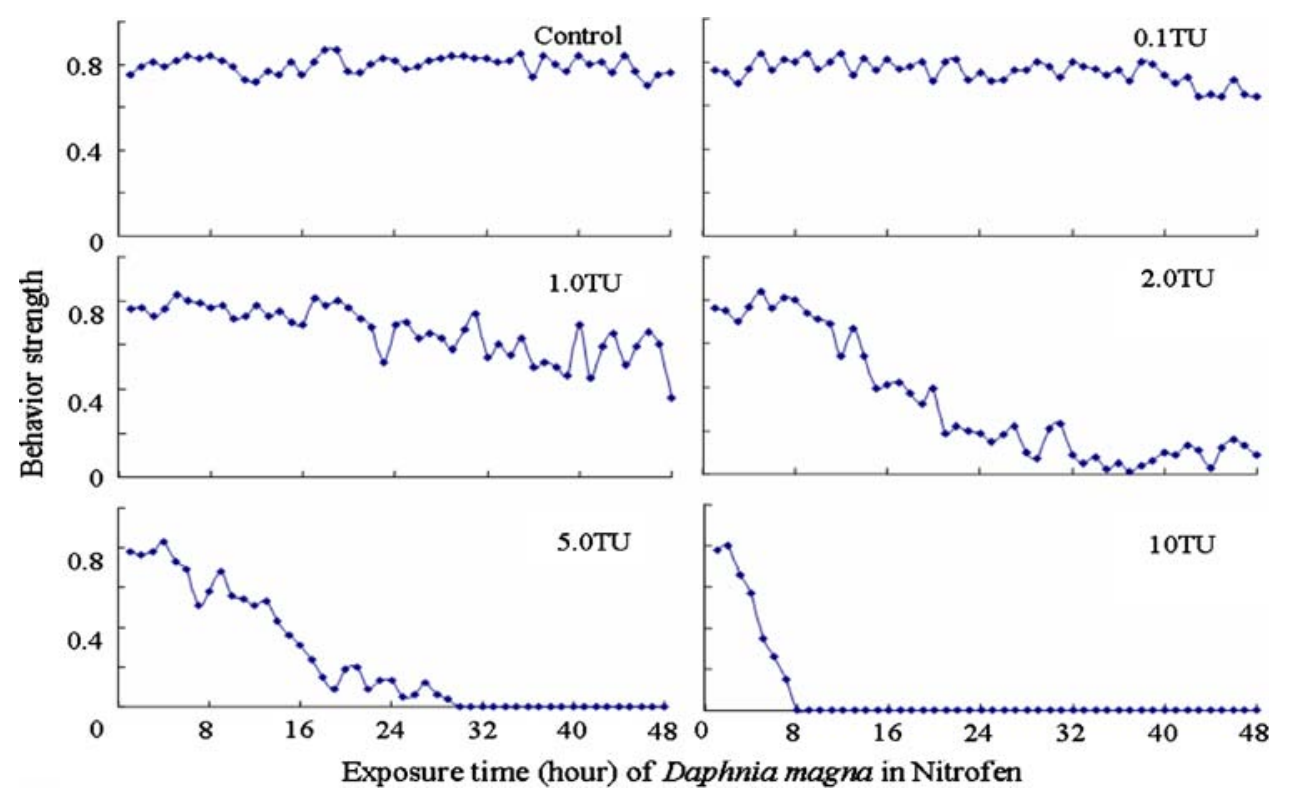

strength changed with exposure time and concentration. Higher concentrations resulted in a greater degree of the behavioral responses, as well as a shorter response time for the first phase behavioral response, which was regarded as avoidance behavior (Sager et al. 2000; Erik et al. 2005; Eriksson Wiklund et al. 2006). Even in the sublethal concentrations $(0.1 \mathrm{TU})$, the first phase behavioral response could be detected.

Though the trends of behavioral responses were similar to each other, there were still some differences among the three contaminants, which may be due to the different ways they exert their toxicity. In the case of deltamethrin exposure, shortly after decrease in behavior strength, there were regulatory responses evidently. The toxicity of deltamethrin was mainly attributed to the neurotoxic stressors, which was similar to the effects of organophosphorous pesticides. The behavior adjustment after exposure to deltamethrin resulted in similar behavioral responses as exposed to organophosphorous pesticides (Ren et al. 2007). However, for chlorothalonil and nitrofen exposures, behavior strength decreased step by step without significant behavior adjustment. Since both chlorothalonil and nitrofen are cytotoxic chemicals, the impairment to animal may develop gradually.

Behavior changes for the general adaptation of organisms in relationship to environment stress have been 


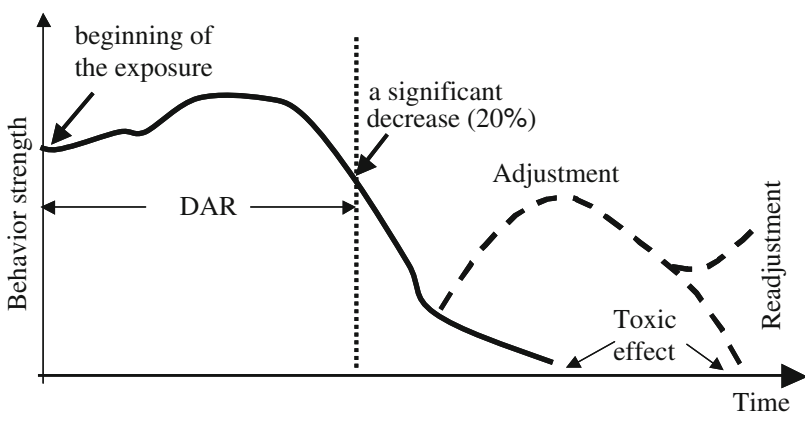

Fig. 4 A generalized behavior response of Daphnia magna under exposure to different chemicals. *Broken line stood for the effects of deltamethrin on the behavioral responses of Daphnia magna, in which there were regulatory responses evidently

reported in previous work (Selye 1973; Gerhardt 2001) and could be seen from Figs. 1, 2, 3.

For deltamethrin, except the $10 \mathrm{TU}$ exposure, the doseeffect relationship included no effect, stimulation, acclimation, adjustment (readjustment at $0.1 \mathrm{TU}, 1.0 \mathrm{TU}$ and $2.0 \mathrm{TU}$ ), and intoxication. The step-wise response was summarized in Fig. 4. For chlorothalonil and nitrofen exposure, the movement behavior in almost all the exposures (except 2.0 TU chlorothalonil) decreased step by step until intoxication. No significant behavior adjustment has been observed. In comparison, chlorothalonil exposure caused a gradually decreased movement behavior followed by a regulatory response, while deltamethrin exposure followed a different adjustment/readjustment pattern. Avoidance that varied with time and concentration upon organisms is an important defense mechanism in organisms, and higher concentrations of contaminants would lead to increased avoidance (Pedder and Maly 1985). Many studies on avoidance response that was regarded as one of the most important behavioral responses of organisms to different contaminant stress had been reported (West and Ankley 1998; Lefcort et al. 2004; Eriksson Wiklund et al. 2006). There was hardly discusses on the on the duration of avoidance response (DAR), which was defined as time between beginning of the exposure and a significant decrease (20\%) in behavior strength (Fig. 4). Therefore, the duration of avoidance behavior, which was mainly affected by toxic unit of the chemical, was investigated.

Figure 5 showed the effects of different contaminant stresses on DAR of Daphnia magna and the relationship was described in Eq. 1. In the equation, $\mathrm{Y}$ represented DAR and $X$ represented the TUs of different chemicals. The equation showed that there was power relationship between DAR and the TU of different contaminants, i.e., the increase of TU would result in a significant decrease in DAR $(p<0.05)$. From Fig. 5 , it could be seen that the DAR-TU relationships for three chemicals were quite similar $(R=0.95)$.

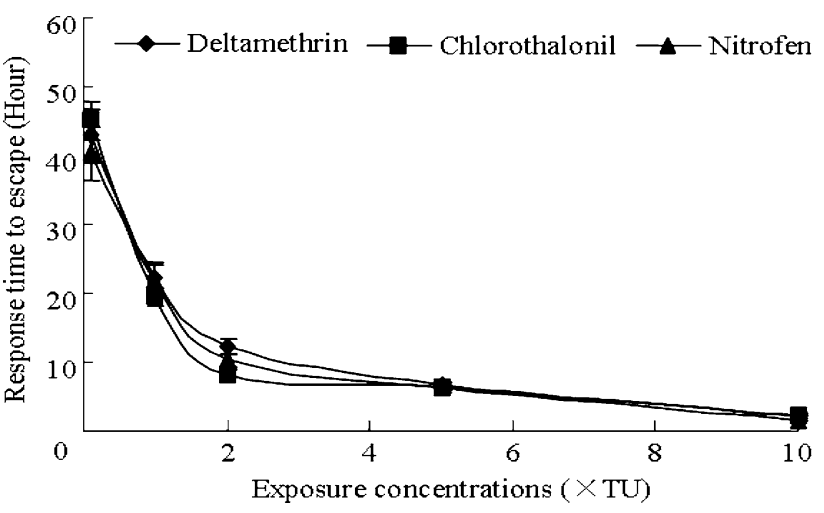

Fig. 5 The duration of avoidance response (DAR) of Daphnia magna in different contaminant stress $(\square$, showed by $\mathrm{M} \pm$ S.D; * $* \leq 0.05)$

Table 2 The equation parameters in different contaminant stress

\begin{tabular}{llll}
\hline Chemicals & Coefficient (a)* & Exponent (b)* & $\begin{array}{l}\text { Correlation } \\
\text { coefficient }(R)\end{array}$ \\
\hline Deltamethrin & $13.87 \pm 1.03$ & $-0.63 \pm 0.06$ & 0.95 \\
Chlorothalonil & $12.85 \pm 1.40$ & $-0.69 \pm 0.06$ & 0.97 \\
Nitrofen & $12.46 \pm 0.93$ & $-0.75 \pm 0.04$ & 0.94 \\
\hline
\end{tabular}

* Showed as $\mathrm{M} \pm$ S.D

$$
\begin{aligned}
& \mathrm{Y}=13.11 \mathrm{X}^{-0.71} \\
& R=0.95
\end{aligned}
$$

The parameters, i.e., the coefficient (a) and the exponent (b) in equation 1 , were calculated for three chemicals (Table 2). There were no significant differences among these parameters for different chemicals, indicating that DAR should be mainly affected by exposure concentration, rather than the toxic characteristics. Therefore, the avoidance behavior of Daphnia magna under exposure of toxic chemical could be used as the early warning thresholds of different toxic chemicals, even though they had different toxic characteristics.

Acknowledgements The work was supported by Chinese Academy of Science (KZCX1-YW-06), National High-Tech R\&D Program of China (2007AA061502) and Tianjin Municipality (06FZZDSH00900).

\section{References}

Baier-Anderson C, Anderson RS (2000) The effects of Chlorothalonilon Oyster hemocyte activation: phagocytosis, reduced pyridine nucleotides, and reactive oxygen species production. Environ Res A 83:72-78. doi:10.1006/enrs.1999.4033

Bejarano AC, Chandler GT, Decho AW (2005) Influence of natural dissolved organic matter (DOM) on acute and chronic toxicity of the pesticides chlorothalonil, chlorpyrifos and fipronil on the meiobenthic estuarine copepod Amphiascus tenuiremis. J Exp Mar Biol Ecol 321:43-57. doi:10.1016/j.jembe.2005.01.003 
Brandsma AE, Tibboel D, Vulto IM, de Vijlder JJ, Ten HaveOpbroek AA, Wiersinga WM (1994) Inhibition of T3-receptor bindingby nitrofen. Biochim Biophys Acta 1201:266-270

Caux PY, Kent RA, Fan GT, Stephenson GL (1996) Environmental fate and effects of chlorothalonil: a Canadian perspective. Crit Rev Env Sci Tec 26:45-93

Duquesne S (2006) Effects of an organophosphate on Daphnia magna at suborganismal and organismal levels: implications for population dynamics. Ecotox Environ Safe 65:145-150. doi:10.1016/ j.ecoenv.2006.01.008

Erik H, Finn-Arne W, Joachim S, Svante W, Holger U (2005) Avoidance behavior and brain monoamines in fish. Brain Res 1032:104-110. doi:10.1016/j.brainres.2004.10.050

Eriksson Wiklund A-K, Börjesson T, Wiklund SJ (2006) Avoidance response of sediment living amphipods to zinc pyrithione as a measure of sediment toxicity. Mar Pollut Bull 52:96-99. doi: 10.1016/j.marpolbul.2005.08.023

Ernst W, Doe K, Jonah P, Young J, Julien G, Hennigar P (1991) The toxicity of chlorothalonil to aquatic fauna and the impact of its operational use on a pond ecosystem. Arch Environ Contam Toxicol 21:1-9. doi:10.1007/BF01055550

Fernández-Alba AR, Hernando MD, Piedra L, Chisti Y (2002) Toxicity evaluation of single and mixed antifouling biocides measured with acute toxicity bioassays. Anal Chim Acta 456: 303-312. doi:10.1016/S0003-2670(02)00037-5

Gerhardt A (2001) A new multispecies freshwater biomonitor for ecological relevant control of surface waters. In: Butterworth F, Gunatilaka A, Gonsebatt ME (eds) Biomonitors and biomarkers as indicators of environmental change: environmental science forum 56, vol 2. Kluwer-Plenum Press, New York

Gerhardt A, Janssens B, Mo Z, Wang C, Yang M, Wang Z (2002) Short-term responses of Oryzias latipes (Pisces: Adrianichthyidae) and Macrobrachium nipponense (Crustacea: Palaemonidae) to municipal and pharmaceutical wastewater in Beijing, China: survival, behavior, biochemical biomarkers. Chemosphere 47:35-47. doi:10.1016/S0045-6535(01)00223-5

Greer JJ, Babiuk RP, Thebaud B (2003) Etiology of congenital diaphragmatic hernia: the retinoid hypothesis. Pediatr Res 53: 726-730. doi:10.1203/01.PDR.0000062660.12769.E6

Heckmann L-H, Callaghan A, Hooper HL, Connon R, Hutchinson TH, Maund SJ, Sibly RM (2007) Chronic toxicity of ibuprofen to Daphnia magna: effects on life history traits and population dynamics. Toxicol Lett 172:137-145. doi:10.1016/j.toxlet.2007. 06.001

ISO (1996a) Water quality-determination of the acute lethal toxicity of substances to a freshwater fish [Brachdanio rerio (HamiltonBuchanan), Teleostei, Cyprinidae]—part 3: flow-through method. ISO/DIS 7346/3

ISO (1996b) Water quality - determination of the mobility of Daphnia magna Straus (Cladocera, Crustacea). ISO 6341, Geneva, Switzerland

Kling DE, Aidlen JT, Fisher JC, Kinane TB, Donahoe PK, Schnitzer JJ (2005) Nitrofen induces a redox-dependent apoptosis associated with increased p38 activity in P19 teratocarcinoma cells. Toxicol In Vitro 19:1-10. doi:10.1016/j.tiv.2004.04.010

Lefcort H, Abbott DP, Cleary DA, Howell E, Keller NC, Smith MM (2004) Aquatic snails from mining sites have evolved to detect and avoid heavy metals. Arch Environ Contam Toxicol 46: 478-484. doi:10.1007/s00244-003-3029-2

Mandrillon A, Saglio P (2007) Waterborne amitrole affects the predatorprey relationship between common frog tadpoles (Rana temporaria) and larval spotted salamander (Salamandra salamandra). Arch Environ Contam Toxicol 53:233-240. doi:10.1007/s00244006-0229-6

Manson JM (1986) Mechanism of nitrofen teratogenesis. Environ Health Persp 70:137-147. doi:10.2307/3430350
Martínez-Jerónimo F, Villaseňor R, Ríos G, Espinosa-Chavez F (2005) Toxicity of the crude oil water-soluble fraction and kaolinadsorbed crude oil on Daphnia magna (Crustacea: Anomopoda). Arch Environ Contam Toxicol 48:444-449. doi:10.1007/s00244003-0220-4

Mascrez B, Mark M, Dierich A, Ghyselinck NB, Kastner P, Chambon $\mathrm{P}$ (1998) The RXR (alpha) ligand-dependent activation function 2 (AF-2) is important for mouse development. Development 125:4691-4707

Moore A, Waring CP (2001) The effects of a synthetic pyrethroid pesticide on some aspects of reproduction in Atlantic salmon (Salmo salar L.). Aquat Toxicol 52:1-12. doi:10.1016/S0166445X(00)00133-8

Narahashi T, Frey J, Ginsburg K, Roy M (1992) Sodium and GABAactivated channels as targets of pyrethroids and cyclodienes. Toxicol Lett 64:429-436. doi:10.1016/0378-4274(92)90216-7

Pedder SCJ, Maly EJ (1985) The effect of lethal copper solutions on the behavior of rainbow trout, Salmo gairdneri. Arch Environ Contam Toxicol 14:501-507. doi:10.1007/BF01055537

Pimpão CT, Zampronio AR, Silva de Assis HC (2007) EVects of deltamethrin on hematological parameters and enzymatic activity in Ancistrus multispinis (Pisces, Teleostei). Pestic Biochem Phys 88:122-127. doi:10.1016/j.pestbp.2006.10.002

Ren ZM, Ma M, Wang ZJ (2006) On-line biomonitoring of accidental drinking water organophosphorous pesticides contamination. Water Wastewater Eng 32:17-20

Ren ZM, Zha JM, Ma M, Wang ZJ, Gerhardt A (2007) The early warning of aquatic organophosphorus pesticide contamination by on-line monitoring behavioral changes of Daphnia magna. Environ Monit Assess 134:373-383. doi:10.1007/s10661-0079629-y

Reynaldi S, Duquesne S, Jung K, Liess M (2006) Linking feeding activity and maturation of Daphnia magna following short-term exposure to fenvalerate. Environ Toxicol Chem 25:1826-1830. doi:10.1897/05-469R.1

Riddell DJ, Culp JM, Baird DJ (2005) Behavioral responses to sublethal cadmium exposure within an experimental aquatic food web. Environ Toxicol Chem 24:431-441. doi:10.1897/04-026R.1

Rosa E, Barata C, Damasio J, Bosch MP, Guerrero A (2006) Aquatic ecotoxicity of a pheromonal antagonist in Daphnia magna and Desmodesmus subspicatus. Aquat Toxicol 79:296-303. doi:10. 1016/j.aquatox.2006.06.019

Sager DR, Hocutt CH, StaufferJr JR (2000) Avoidance behavior of Morone americana, Leiostomus xanthurus and Brevoortia tyrannus to strobe light as a method of impingement mitigation. Environ Sci Policy 3:393-403. doi:10.1016/S1462-9011(00)00046-0

Saglio P, Trijasse S (1996) Behavioral effects of waterborne carbofuran in Goldfish. Arch Environ Contam Toxicol 31(2): 232-238. doi:10.1007/BF00212371

Sandbacka M, Christianson I, Isomaa B (2000) The acute toxicity of surfactants on fish cells, Daphnia magna and fish-a comparative study. Toxicol In Vitro 14:61-68. doi:10.1016/S0887-2333(99) 00083-1

Scarfe AD, Jones KA, Steele CW, Kleerekoper H, Corbett M (1983) Locomotor behavior of four marine teleosts in response to sublethal copper exposure. Aquat Toxicol 2:335-353. doi:10. 1016/0166-445X(82)90020-0

Selye H (1973) The evolution of the stress concept. Am Sci 61:692699

Şener Ural M, Sağlam N (2005) A study on the acute toxicity of pyrethroid deltamethrin on the fry rainbow trout (Oncorhynchus mykiss Walbaum, 1792). Pestic Biochem Phys 83:124-131. doi: 10.1016/j.pestbp.2005.04.004

Soderlund DM, Bloomquist JR (1989) Neurotoxic actions of pyrethroid insecticides. Ann Rev Entomol 34:77-96. doi:10.1146/ annurev.en.34.010189.000453 
Steele CW, Strickler-Shaw S, Taylor DH (1989) Behavior of tadpoles of the bullfrog, Rana catesbeiana, in response to sublethal lead exposure. Aquat Toxicol 14:331-343. doi:10.1016/0166-445X (89)90031-3

Sturm A, Hansen PD (1999) Altered cholinesterase and monooxygenase levels in Daphnia magna and Chironomus riparius exposed to environmental pollutants. Ecotox Environ Safe 42:915. doi:10.1006/eesa.1998.1721

Tillman RW, Siegel MR, Long JW (1973) Mechanism of action and fate of the fungicide chlorothalonil (2,4,5,6-tetrachloroisophalonitrile) in biological systems: 1. Reactions with cells and subcellular components of Saccharomyces pastorians. Pestic Biochem Phys 3:160-167. doi:10.1016/0048-3575(73)90100-4

Tomasik P, Warren DM (1996) The use of Daphnia in studies of metal pollution of aquatic systems. Environ Res 4:25-64

Untersteiner H, Kahapka J, Kaiser H (2003) Behavioral response of the cladoceran Daphnia magna STRAUS to sublethal Copper stress - validation by image analysis. Aquat Toxicol 65:435-442
Villegas-Navarro A, Romero GMC, Rosas LE, Dominguez AR, Sachetin MW (1999) Evaluation of Daphnia magna as an indicator of toxicity and treatment efficacy of textile wastewaters. Environ Int 25(5):619-624. doi:10.1016/S0160-4120(99) 00034-3

West CW, Ankley GT (1998) A laboratory assay to assess avoidance of contaminated sediments by the freshwater Oligochaete Lumbriculus variegates. Arch Environ Contam Toxicol 35:20 24. doi:10.1007/s002449900343

WHO (World Health Organization) (1990) Deltamethrin, environmental health criteria 97. World Health Organization, Geneva, p 133

Wiles JA, Jepson PC (1994) Substrate-mediated toxicity of deltamethrin residues to beneficial invertebrates: estimation of toxicity factors to aid risk assessment. Arch Environ Contam Toxicol 27:384-391. doi:10.1007/BF00213175 